\title{
Best Practices for Scalloping: From the Boat to Your Plate ${ }^{1}$
}

\author{
Brittany Hall-Scharf, Sarah Ellis, and Savanna Barry²
}

\section{Introduction}

During the summer months, residents and visitors flock to certain parts of Florida's Gulf Coast for recreational scallop season. To have a safe and enjoyable experience, it is important to be familiar with the legal requirements for boating, best practices for scalloping, and how to safely prepare your catch (Hall-Scharf 2018).

Ready to participate in the fun and snack on Florida's favorite summertime fare? This publication will provide an overview of best practices for scalloping from the boat to your plate.

\section{Scalloping and Boating}

By following these recommended guidelines, you can increase the chances that your scalloping adventure goes smoothly.

\section{Familiarize yourself with scallop seasons, zones and bag limits.}

Recreational harvest of bay scallops is only allowed in specific Gulf Coast counties during limited seasons. This information changes from year to year. Before planning your trip, be sure to check specific locations, bag limits, and season dates, which can be found on the Florida Fish and Wildlife Conservation Commission (FWC) website: http:// myfwc.com/fishing/saltwater/recreational/bay-scallops/.

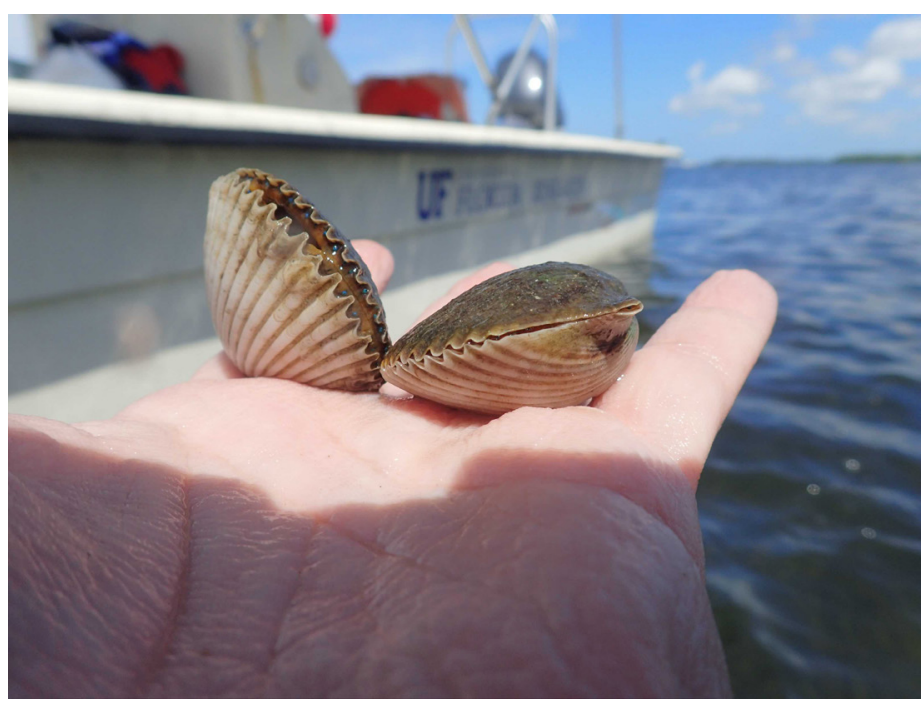

Figure 1. Freshly harvested scallops can be a great addition to a summertime meal.

Credits: Josh Patterson, UF/IFAS School of Forest Resources and Conservation, Program in Fisheries and Aquatic Sciences

\section{Develop a safety protocol.}

Before you launch, leave a float plan with someone on shore just in case officials need to be called for assistance. This FWC template is a good place to start: http://myfwc.com/ media/100268/Boating_FLOAT_PLAN.pdf.

1. This document is SGEF-252, one of a series of the Florida Sea Grant College Program, UF/IFAS Extension. Original publication date July 2018. Visit the EDIS website at http://edis.ifas.ufl.edu.

2. Brittany Hall-Scharf, UF/IFAS Extension Florida Sea Grant agent for Hernando County, Brooksville, FL 32604; Sarah Ellis, UF/IFAS Extension Family and Consumer Sciences agent for Citrus County, Lecanto, FL 34461; and Savanna Barry, UF/IFAS Extension Florida Sea Grant Agent, Nature Coast Biological Station, Cedar Key, FL 32625.

The Institute of Food and Agricultural Sciences (IFAS) is an Equal Opportunity Institution authorized to provide research, educational information and other services

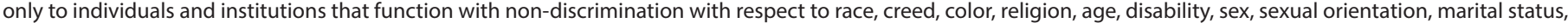

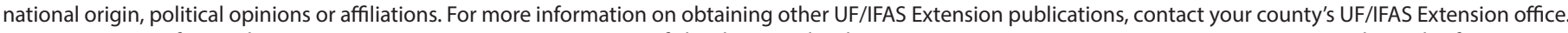
U.S. Department of Agriculture, UF/IFAS Extension Service, University of Florida, IFAS, Florida A \& M University Cooperative Extension Program, and Boards of County Commissioners Cooperating. Nick T. Place, dean for UF/IFAS Extension. 
Make sure everyone in your group knows the answers to the following questions before heading out:

- Where on the vessel is the first aid kit? Flares? Personal flotation devices? Throwable flotation device? Soundproducing device? Fire extinguisher? Fresh drinking water?

- Does everyone have sun protection such as sunscreen or protective clothing?

- Is there something on board to provide relief from a stinging animal? (Note: A small spray bottle of white vinegar for neutralizing stings can be a useful addition to a first aid kit.)

Accidents can happen easily out on the water, and it is important that everyone on board is familiar with the location and use of these safety items. Be sure to have a plan of action if an exhausted swimmer needs to be rescued.

Refer to FWC's website (http://myfwc.com/boating/regulations/) for a list of required boating safety equipment.

\section{Be aware of approaching storms and plan accordingly.}

Thunderstorms are common during Florida's summer months, and, according to the National Lightning Detection Network (NLDN), Florida has the highest density of lightning strikes in the United States (NLDN 2018). Be aware of the forecasted weather, and have an exit plan for your group. If possible, keep a marine VHF radio on board because cell phones may not have a good signal on the water.

A good plan is to start your day at the site farthest from your launch point and work your way back to your starting point in the afternoon, when storms are more likely.

However, sometimes storms approach so quickly that there is no time to escape. Be sure to plan for this scenario as well. Make sure all passengers know what to do if you are forced to wait out the storm, or if the vessel or a passenger gets struck by lightning.

Some items to include in your lightning safety plan:

1. Select a safe harbor and get off the water. If you hear thunder or see a storm, do not wait until it is too late. If you can hear thunder, you are close enough to the storm to be struck by lightning. Begin to motor away from the storm and find a safe harbor. It may not always be the harbor from which you launched.

\section{If you get stuck on the water, stay low on the boat. If} possible, anchor securely on the lee side of a small island.
Find the lowest point on the boat that is away from any metal objects. Get inside of the cabin, if possible, and remove all jewelry. Do not jump into the water or swim away from the boat.

3. Lower antennas and disconnect power. This will help prevent equipment damage. Make sure everyone knows if there are any grounding protection systems on board and to stay away from them, if possible.

4. Be quiet and aware of surroundings. Watch which way the storm travels, and stay put until it has passed. Do not use the VHF radio unless necessary, and be observant of others on board.

Refer to the BoatUS (http://www.boatus.com/pressroom/ release.asp?id=676) and the NOAA (https://www.weather. gov/safety/lightning) websites for additional guidelines on lightning safety for boaters.

\section{Have an observer stay on board while others are scalloping.}

Leaving a vessel unmanned can be dangerous. The anchor may not hold, or the vessel might take on water. Thunderstorms may approach, or another boater may get too close. Have a lookout stay on board for those swimming just in case someone needs assistance. The lookout should notify anyone who swims too far from the vessel for a quick rescue.

\section{Stay within the required range of your vessel.}

You must make reasonable efforts to stay within 300 feet of a divers-down flag in open waters and within 100 feet of a flag within rivers, inlets, or navigation channels. When snorkeling in search of scallops, look up often and check that you are near your boat. It can be very easy to unknowingly venture too far from the vessel while scalloping. Being aware of the vessel's location is important to prevent injuries and exhaustion. It will also keep you from having to drag your scallop catch long distances while in the water.

\section{Don't forget to display the divers-down flag while snorkeling.}

A divers-down flag is required by law and should be displayed above the vessel's highest point or tethered to the person whenever a snorkeler or diver is in the water. Flags displayed on vessels must be at least 20 inches by 24 inches and have a stiffener to keep the flag unfurled. If the flag is tethered to a diver or a snorkeler, the divers-down flag must be at least 12 inches by 12 inches. 


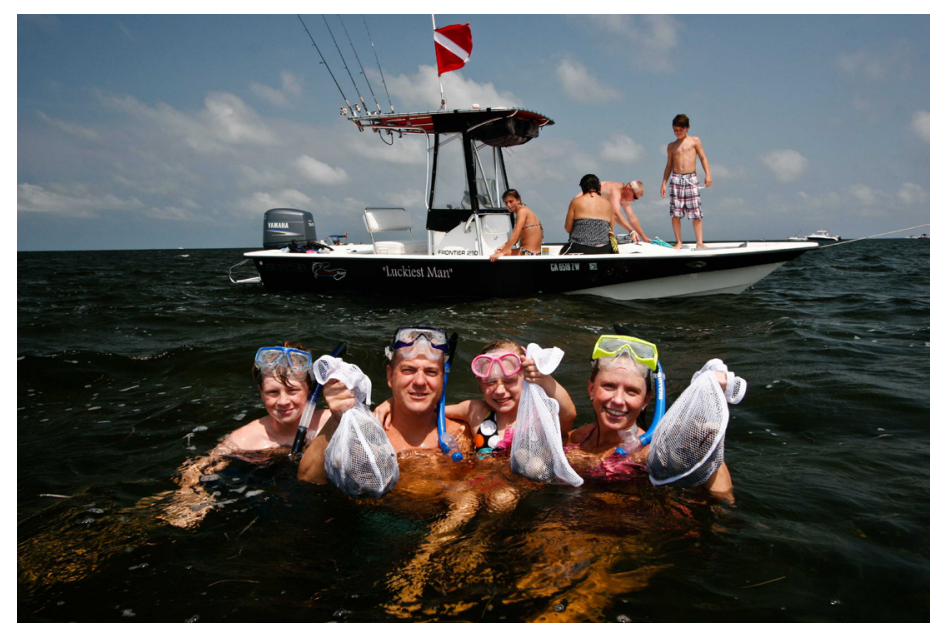

Figure 2. When searching for scallops, try not to venture too far from the boat.

Credits: Tommy Thompson

\section{Take down the divers-down flag before moving to another location.}

A raised dive flag is a way to inform others that there are snorkelers and/or divers below. Leaving the flag displayed while motoring is not only against the law but can confuse other boaters and increase the chance of someone getting injured.

Refer to FWC's website (http://myfwc.com/boating/ regulations/) for additional information regarding the divers-down flag.

\section{Be aware of changing tides and use caution when boating near seagrass.}

The tides flooding onto or leaving the grass flats create strong currents. Swimming against tidal currents is difficult and can increase the chances of exhaustion. If possible, begin by swimming into the current when starting your search for scallops. That way, it will be easier to return to the boat when you are finished because you will be swimming with the current.

During outgoing tides, vessels can be stranded in shallow seagrass areas where scalloping is popular. Always check the tides for your area before venturing out, and plan your trip accordingly. Tides will be stronger around the new and full moon. To protect seagrass meadows, avoid boating over seagrass when possible. When you must boat over seagrass, be sure to slow down and trim up your motor, and always push off of seagrass if you run aground. Do not attempt to motor off because this can cause further damage to the fragile seagrasses, which are important to the health of the scallop population. Refer to the Responsible Boating
Protects Seagrass Meadows fact sheet (http://edis.ifas.ufl. edu/sg151) for additional tips on how to safely navigate seagrass areas.

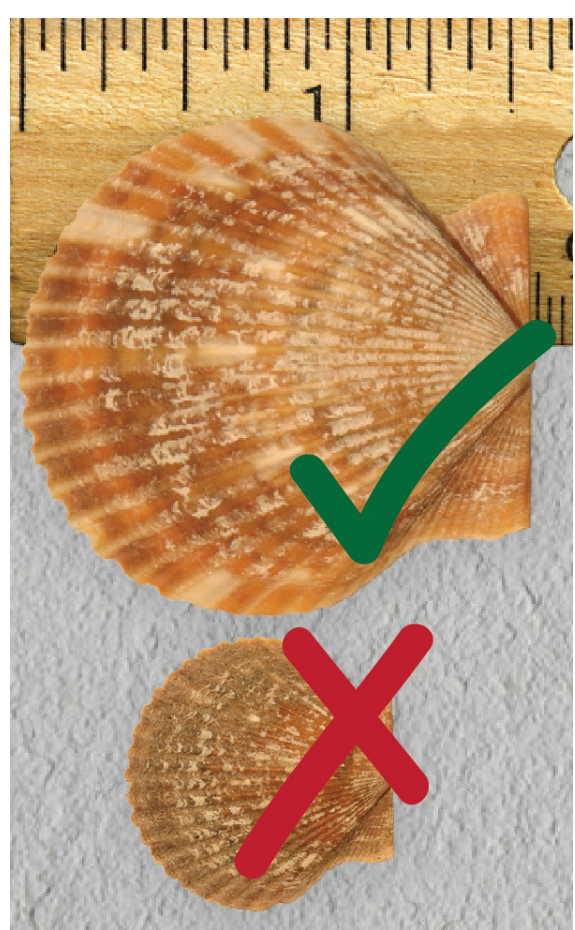

Figure 3. To make sure your scallop is large enough to keep, measure the shell from top to bottom.

Credits: Florida Sea Grant

\section{Only keep scallops that are 1.5 inches or larger, and throw anything smaller back.}

Keeping just the larger scallops and returning smaller ones helps the scallop population and helps you, as well. Scallops live about one year before spawning and dying off naturally. Most spawn in the fall, though some survive through the winter and spawn again in spring.

The larvae scallops produce swim as plankton for about two weeks before settling onto seagrass blades. The young continue to grow while attached to the grass blades by a mass of silk-like filaments called a byssus. They can, however, start swimming at any time to avoid predators like crabs, octopuses, shell-crushing fish, or even people!

If you collect only the larger scallops, you will ensure fewer are harvested and the smaller scallops make it to the fall to spawn and contribute to the population. Larger scallops also produce enough meat to make cleaning them worthwhile. 


\section{Follow general harvesting guidelines.}

Here are some general harvesting guidelines:

- Only recreational harvesting is allowed.

- Harvesters need a Florida saltwater fishing license unless:

- Harvest only by hand or with a landing dip net.

- While snorkeling, place scallops in a mesh bag, rather than in a pocket or in your swimsuit. They can pinch!

- Daily limits are 2 gallons of whole scallops (in the shell), or 1 pint of scallop meat per person per day.

- In addition, no more than 10 gallons of whole scallops or $1 \frac{1}{2}$ gallon of scallop meat may be processed aboard any vessel at any time.

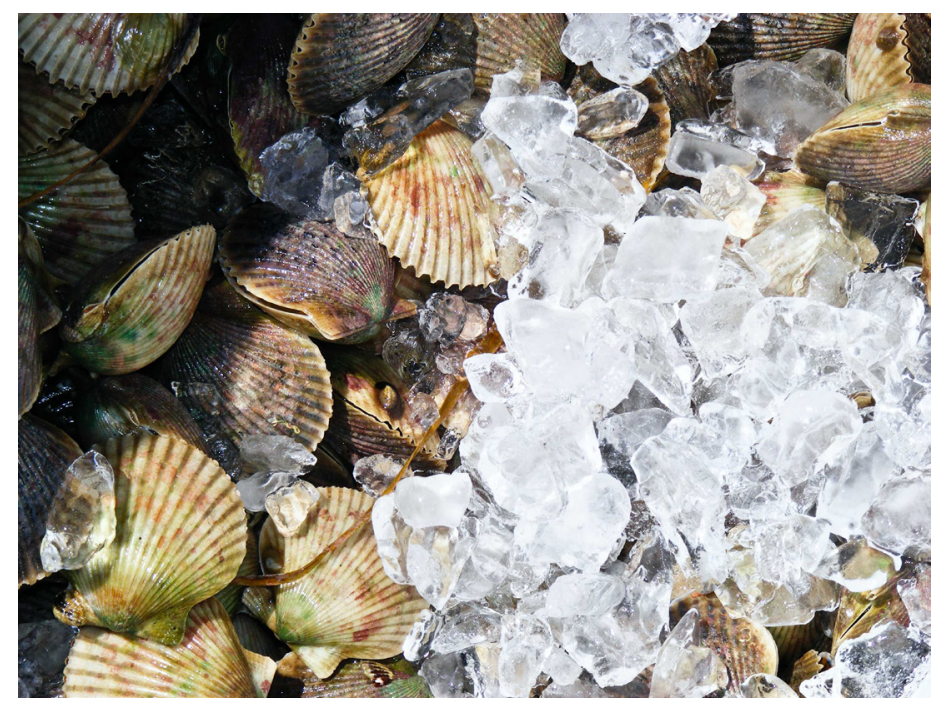

Figure 4. Once scallops are collected, be sure to place them on ice. Credits: Tommy Thompson

\section{Preparing Your Catch}

\section{Place scallops on ice, or attach catch bags to a cleat and let them hang in the water.}

Scallops are quite sensitive to drying out and will quickly die if left exposed in the hot sun. Leaving them to sit in the heat also increases the risk for contamination.

Here are two ways to handle your scallops:

1. When brought to the boat, scallops should be immediately placed on ice in a cooler at $41^{\circ} \mathrm{F}$ or below for the trip to shore. The intent is not to keep the scallops alive, but to reduce opportunities for harmful bacterial growth. Scallops will usually die shortly after being placed on ice, especially if fresh water gets into their shells. The best way to store your scallops is to position them in a cooler above the accumulating melt water from any ice. It's best to pull the drain plug and let the melt water out. A moist towel can be placed between the ice and the scallops to temper the thermal shock that will immediately kill the scallops and to absorb any seepage from the scallops. Placing scallops on ice also makes them easier to open because the muscle that holds the shells together relaxes.

2. Another safe method is to hang the scallops in extra catch bags from a cleat, leaving them in the water until you head home. Just be sure to pull the bags before you weigh anchor! At this point, try to cool your scallops.

If you decide to clean the scallops as you harvest them, cool the cleaned meat as quickly as possible, taking care not to allow it to become contaminated with melting ice water.

\section{Practice good personal hygiene to prevent contamination.}

Practicing good personal hygiene is the easiest way to prevent a foodborne illness. Before cleaning scallops at home or on the boat, wash your hands. If at home, wash with warm soapy water for at least 20 seconds. Be sure to include your wrists, between your fingers, and under your fingernails. Dry your hands using a paper towel or a clean towel.

If on the boat, set up a temporary hand washing station with clean, drinkable water, soap, and paper towels. Follow the steps listed above to wash your hands. If you get cut or scraped, treat the wound immediately and put on gloves before cleaning more scallops.

It is also important to wash all utensils, cleaning tools, and containers before using them to clean scallops. This can be done in a dishwasher or by hand. If using a dishwasher, follow manufacturer's guidelines. If washing by hand, you will need to wash, rinse, and sanitize your items. To learn how to properly wash items without a dishwasher visit: http://edis.ifas.ufl.edu/fy1403.

\section{Follow recommended cleaning guidelines.}

Cleaning scallops is a messy job. To learn how to properly clean scallops, watch this tutorial from Florida Sea Grant: https://www.youtube.com/watch?v=0aLotAaBxeM.

\section{Materials needed:}

- A scallop, clam, or oyster knife. A butter knife or teaspoon can also be used to open the shells and remove the wanted muscle. A sharp tool is not recommended. 


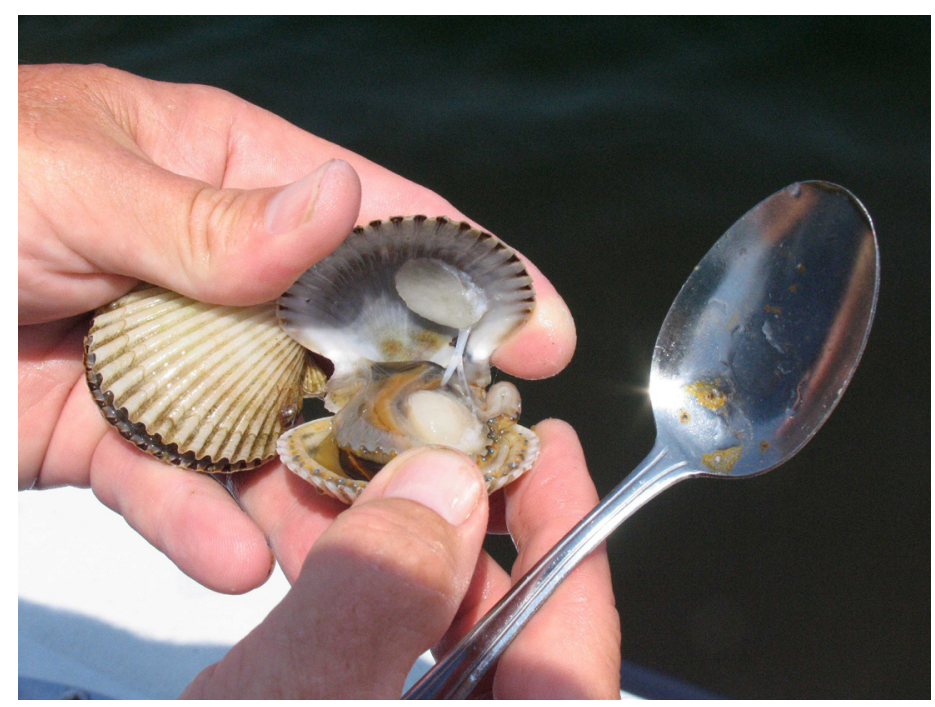

Figure 5. A spoon or butter knife can be used to clean scallops. Credits: Tommy Thompson

- A plastic food-storage container with a tight-fitting lid

- A cooler of ice or a refrigerator

- A disposal bucket

\section{General cleaning procedure:}

1. Wash all cleaning tools, utensils, and containers before cleaning per recommendations above.

2. Allow scallops to cool on ice until shells begin to open.

3. Locate the dark shell of the scallop and place upward in the palm of your hand.

4. Insert the cleaning tool between the shell and the muscle, and detach the muscle from the upper shell.

5. Discard the upper shell into the disposal bucket.

6. Holding the remaining bottom scallop shell, carefully pull the remaining soft organs away from the muscle and discard them in the disposal bucket. This should leave nothing but the desired muscle attached to the bottom shell.

7. Detach the remaining muscle and put it into your lidded food storage container.

8. Discard the remaining shell in the disposal bucket.

When cleaning scallops, clean your hands and your utensils when they become dirty, or at least every four hours if you have been cleaning scallops uninterrupted. (Wash your gloved hands or simply change to a new pair of gloves if you are wearing gloves.)
Store scallop meat in a clean container with a tight-fitting lid. If you clean your catch on the boat, store your container of scallop meat on ice and transfer it to the refrigerator as soon as possible.

You may prefer to hire someone to clean your scallops for you. If you choose to do so, ensure there are proper handwashing stations with running water accessible to the workers. Check to see that whole scallops are kept in the shade and cool, and that scallop meats are stored on ice once shucked and awaiting pickup.

\section{Do not dispose of scallop shells in channels, canals, marinas, springs, or boat ramps.}

Be courteous of other scallopers, and move your boat away from the scalloping areas before cleaning. It's no fun scalloping where others are cleaning their catch.

Shells and soft tissues should be disposed of in open Gulf of Mexico waters with moderate to strong currents that are not channels, canals, marinas, springs, or boat ramps. Shells could fill in these areas, incurring costs to remove the shells and causing negative impacts to wildlife and navigation. In addition, dumping shells and tissues into areas with little to no current does not allow the materials to be dispersed to the surrounding areas and may degrade water quality by causing increases in bacteria and algae blooms. Finally, shells disposed of in shallow swimming areas, such as springs or sandbars, pose a serious hazard to swimmers.

If you cleaned your catch on shore, you can dispose of shells in a lidded trash can or keep shells to use for crafts or garden cover. Try placing the shells in a net bag and hanging them in the water. Small fish and crabs will be happy to clean the shells for you.

\section{Rinse meat and use caution by cooking scallops before serving.}

Shellfish like oysters, clams, and scallops filter water and can accumulate bacteria and viruses that might be found in the surrounding waters. Oysters and clams are normally harvested from regulated and tested waters, and so are relatively safe, but the waters where scallops are harvested are not regulated or tested. Therefore, it is not recommended to eat scallops raw, especially the gut, or dark part surrounding the white meat.

Before cooking scallops, rinse the meat with cold water. This will help remove any unwanted dirt or organs missed 
during the shucking process. Blotting with a paper towel or other item is not recommended because it increases the risk of introducing pathogens to the meat. Use cold water to rinse the delicate meat to avoid cooking it prematurely.

\section{Conclusion}

Following these best practices can help everyone continue to enjoy recreational scalloping for many Florida summers to come. A safety protocol and float plan can help everyone on board prevent accidents and respond quickly and effectively to a problem, if one develops. Properly storing and cleaning your scallops can also help prevent dangerous foodborne illnesses. Additional up-to-date safety training, whether boating or medical, is always recommended.

\section{Additional Resources}

For more information about recreational scalloping in Florida, visit the Florida Sea Grant website (https://www. flseagrant.org/fisheries/scalloping/) or download one of these scalloping brochures:

- Citrus County: http://edis.ifas.ufl.edu/sg147

- Hernando County: http://edis.ifas.ufl.edu/sg148

- Pasco County: http://edis.ifas.ufl.edu/sg157

- Taylor County: http://edis.ifas.ufl.edu/sg146

- Wakulla County: http://edis.ifas.ufl.edu/sg149

\section{Citations}

Hall-Scharf, B.J. 2018. Recreational Harvest of the Florida Bay Scallop: Hernando County. SGEF-235. Gainesville: University of Florida Institute of Food and Agricultural Sciences. http://edis.ifas.ufl.edu/sg148

National Lightning Detection Network (NLDN). 2018. Rank of Cloud-To-Ground Flash Densities by State from 2008 to 2017. Vaisala, Inc. https://www.weather.gov/media/ safety/08-17Flash_Density_State.pdf 